\title{
In vivo study of corneal responses to increased intraocular pressure loading
}

\author{
Ahmed Elsheikh ${ }^{1,2}$, Charles W. McMonnies ${ }^{3}$, Charles Whitford ${ }^{1 *}$ and Gavin C. Boneham ${ }^{3}$
}

\begin{abstract}
Background: The cornea is responsible for two-thirds of the eye's refractive power which is a function of the shape and refractive index. The aim of this present study is to examine human eyes in vivo for corneal shape changes in response to short-term elevation in intraocular pressure.

Methods: Videokeratographic and tonometric assessments at baseline were compared with the same assessments when intraocular pressure was elevated to approximately double (199 $\pm 22 \%)$ the baseline levels using ophthalmodynamometer applanation of the sclera. Composite maps of the cornea and limbus were created by combining topographical assessments for central, nasal, temporal, inferior and superior fixation. Numerical finiteelement simulations were custom built for each subject and the stiffness distribution across corneal surface modified to achieve matches between simulated and experimental data.
\end{abstract}

Results: The stiffness distributions required to achieve simulation-experimental matches showed a consistent trend with the $2.5 \mathrm{~mm}$ annulus bounded by the limbus showing a mean stiffness reduction of $47.3 \pm 10.8 \%$ compared with the central cornea $(P=0.001)$.

Conclusions: Corneal structure appears to provide the central cornea with a greater stiffness compared with the peripheral cornea and associated greater tolerance to elevation in intraocular pressure, consistent with the need for stable corneal refraction and vision. The method adopted to examine corneal biomechanical performance in vivo may have applications in additional studies.

Keywords: Corneal biomechanics, Topography, Numerical simulation

\section{Background}

Corneal biomechanical behavior is primarily a function of the stroma, which represents the bulk of corneal thickness, and is composed of lamellae of collagen fibrils embedded within a matrix of proteoglycans [1]. There are approximately 300 lamellae through the center of the normal cornea, running uninterrupted from limbus to limbus, rather like thin belts up to $0.2 \mathrm{~mm}$ broad and about $2 \mu \mathrm{m}$ thick [2]. The number of lamellae increases by branching as the cornea thickens toward the periphery reaching about 500 at the limbus [3].

$\mathrm{X}$-ray scattering has unambiguously demonstrated that the majority of collagen fibrils in the central region of human corneas adopt a preferred orientation in the inferior-superior (vertical) or nasal-temporal (horizontal)

\footnotetext{
* Correspondence: whitford@liv.ac.uk

${ }^{1}$ School of Engineering, University of Liverpool, Brownlow Hill, Liverpool L69 $3 \mathrm{GH}, \mathrm{UK}$

Full list of author information is available at the end of the article
}

directions $[4,5]$. The transition from meridional orientation at the center to circumferential at the limbus has been the subject of several studies, and most data indicate that the central meridional fibrils undergo a smooth transition to become circumferential as the limbus is approached [5-8]. At the limbus, these fibrils merge with the limbal annulus and possibly another population of circumferential fibrils originating from the sclera [5]. This change in collagen orientation from the apex to the limbus could be expected to lead to regional variations in biomechanical performance - in particular a reduction in corneal stiffness (increase in compliance) due to the reducing content of meridional fibrils in the transition zone [9] - and may affect corneal shape variation under changes in mechanical loading such as intraocular pressure (IOP) elevation.

The shape of the cornea is a function of a number of structural and biomechanical parameters, the most

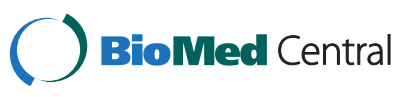

(c) 2016 Elsheikh et al. Open Access This article is distributed under the terms of the Creative Commons Attribution 4.0 International License (http://creativecommons.org/licenses/by/4.0/), which permits unrestricted use, distribution, and reproduction in any medium, provided you give appropriate credit to the original author(s) and the source, provide a link to the Creative Commons license, and indicate if changes were made. The Creative Commons Public Domain Dedication waiver (http://creativecommons.org/publicdomain/zero/1.0/) applies to the data made available in this article, unless otherwise stated. 
important of which are the material thickness and stiffness (as measured by the tangent modulus), as well as the IOP [10]. Examination of the biomechanical performance of the cornea with respect to shape has frequently been limited to ex vivo animal and human studies and by associated methodological deficiencies. These limitations have recently been reviewed [11].

The purpose of this study is to examine human eyes in vivo, explore corneal shape changes in response to short-term rises in IOP, and relate any such changes to possible regional variations in corneal stiffness. The study builds on earlier work, in which the central corneal shape was examined in normal human eyes under conditions of IOP elevated to a range of 374-443\% greater than normal [12]. Under this level of IOP elevation, the central corneal shape and refraction showed only minor changes. However, such studies using normal videokeratographic data collection methods can be limited to findings that do not allow analysis of significant areas of the peripheral cornea and may fail to detect regional differences in response. This study aims to extend videokeratographic data collection further into the peripheral cornea and to utilize the extended data, alongside numerical simulations of full eye globes, to determine the biomechanical performance of the transition peripheral zone compared with that at the center.

\section{Methods}

Seven Caucasian participants with an age range of over 50 years were selected to include only healthy eyes with no history or evidence of corneal abnormalities or relevant systemic diseases.

\section{Experimental data}

The methods used to increase IOP and monitor corneal topography in this study have been described and evaluated previously [13]. Baseline and elevated IOP were measured (mean of three readings for the left eye of each subject) using an Expert NCT Plus noncontact tonometer (Reichert Ophthalmic Instruments, Depew, NY), which was calibrated according to the manufacturer's guidelines. A Medmont E300W computerized videokeratographic corneal topographer (Medmont Vermont, Victoria, Australia) was used to record baseline topography data for the same eyes. The topography assessment was based on elevation relative to a vertical plane that was tangential to the cornea at its front-most point and was determined independently of eye position. The instrument has a 32-ring placido cup target with the potential to provide corneal coverage from $0.25 \mathrm{~mm}$ to $11 \mathrm{~mm}$ diameter. For this instrument, manual alignment and automatically initiated image capture are combined with progressive accumulation and storage of the best three images. Each image is analyzed for centering, focus and stability, and then rated to yield a percentage figure for quality, after correction for detected defocus and alignment errors. Image ratings of over $75 \%$ are deemed by the manufacturer to be acceptable [14]. However, image capture was continued in this study until three optimized images with a quality rating of at least $98 \%$ were captured and retained for analysis. The remaining images were discarded. This procedure was intended to maximize measurement reliability.

After normal alignment readings were recorded, the measurements were immediately repeated with subjects instructed to alter fixation approximately $10^{\circ}$ to the left and right and then down and up so that data from the peripheral cornea and the limbus could be recorded nasally, temporally, superiorly and inferiorly. The three sets of optimized corneal elevation data produced by Medmont software for each position were analyzed to derive the corresponding average topography, and the five average maps (one aligned and four with controlled misalignment) were processed mathematically as explained below to obtain a corneal map covering the whole corneal surface and the limbus-with map coverage diameter extending to $14 \mathrm{~mm}$.

An ophthalmodynamometer (ODM) compressive force against the sclera was used to elevate IOP by application of the instrument foot plate to the adnexal skin. The $10 \mathrm{~mm}$ diameter metal foot plate was positioned on the temporal side under the lower lid, in line with the inferior palpebral furrow. The compressive ODM force applanates the sclera and the intraocular fluid displaced by the applanation is accommodated by increased distending forces on the sclera and cornea, and IOP is raised accordingly [15]. The IOP elevation varies with normal IOP and in proportion to the volume of the intraocular fluid displaced. The force delivered by the hand-held ODM approached a standard level by maintaining the same instrument setting, and a horizontal position for the force indicator throughout all measurements. Efforts to maintain the repeatability of the level of force delivered included the instrument footplate being applied tangentially to the scleral surface. By this means, an approximately equal distribution of the compressive force over the footplate area, and corresponding area of scleral applanation and associated force application were maintained for all measurements. Tonometry readings were repeated under this ODM force to assess the elevation in IOP induced during the videokeratographic assessments. All topographic assessments were then repeated with IOP elevated under the same ODM force and the same procedures described above for baseline measurements.

The study protocol was approved by the Human Research Ethics Advisory panel of the University of New South Wales, in accordance with the tenets of the Declaration of Helsinki. Ethics approval (number HC12467) was granted in response to this application. 
The purpose of the study was explained to all subjects who read and signed an informed consent form.

\section{Analysis of elevation data}

The elevation data took the form of Cartesian point coordinates $(x, y, z)$ with the center point of each data set located at $(0,0,0)$. Central and peripheral maps of each eye were combined to cover the whole surface of the cornea and hence enable construction of an eye-specific numerical model. The map combination process relied on the introduction to peripheral maps of $3 \mathrm{D}$ displacements and rotations, which were optimized using the least squares method to reduce the difference in $\mathrm{z}$ coordinates between points on the peripheral maps and corresponding points on the central map with the same $\mathrm{x}$ and $\mathrm{y}$ coordinates. In order to overcome the discretized nature of the data and to enable the unrestrained matching of points on central and peripheral maps, central maps were fitted to Zernike polynomials such that the difference between the $\mathrm{z}$ coordinates between the two data sets could be obtained at any point $(\mathrm{x}, \mathrm{y})$ on the peripheral maps.

Zernike polynomials of orders between 3 and 8 were attempted for all 7 central maps, and it was found that the error of fit reduced gradually with higher orders down to $1.5 \pm 1.2 \mu \mathrm{m}$ with eighth order Zernike polynomials, see Table 1 . Initially, all data points were included in this step. However, due to the relatively larger fitting errors at the outer-most points $[16,17]$, it was decided to exclude the points within an outer ring with $0.8 \mathrm{~mm}$ width (approximately $16 \%$ of all points), reducing the error of fit from $1.5 \pm 1.2$ to $0.5 \pm 0.4 \mu \mathrm{m}$. Each of the corresponding peripheral data sets were then matched to the central set by first excluding the edge data similar to the central maps, then making an initial assumption of a reasonable shift involving 3 displacements $\left(x_{0}, y_{0}\right.$, $\left.z_{0}\right)$ and 3 rotations $(\alpha, \beta, \gamma)$, Fig. 1 . The area of overlap between the peripheral and central sets was determined according to the $\mathrm{X}$ and $\mathrm{Y}$ coordinates. Points in the peripheral set within the area of overlap were identified, and for each point $\mathrm{i}\left(\mathrm{x}_{\mathrm{pi}}, \mathrm{y}_{\mathrm{p}}, \mathrm{z}_{\mathrm{pi}}\right)$ a corresponding point on the central map $\left(\mathrm{x}_{\mathrm{ci}}=\mathrm{x}_{\mathrm{pi}}, \mathrm{y}_{\mathrm{ci}}=\mathrm{y}_{\mathrm{pi}}, \mathrm{z}_{\mathrm{ci}}\right)$ was located using the Zernike polynomials, Fig. 2. Figure 3 provides the topography in the form of Cartesian points after the matching has been performed. The error of fit $\left(\mathrm{z}_{\mathrm{pi}}-\mathrm{z}_{\mathrm{ci}}\right)$ was calculated for all points within the overlap area and the root mean square (RMS) of error $\sqrt{\frac{1}{n} \sum_{i=1}^{n}\left(z_{p i}-z_{c i}\right)^{2}}$, where $n$ =number of points on the peripheral map within the overlap area with the central map, was determined. The least squares method was then employed to reduce the RMS of error of fit to a minimum while changing the values of the 3 displacements and 3 rotations introduced into the peripheral map. The values of the RMS of error had an average and standard deviation values of $4.5 \pm 2.4 \mu \mathrm{m}$. After fitting all four peripheral maps, one by one, to their corresponding central map, all five data sets were again fitted to eighth order Zernike polynomials, and in this step the average error of fit was $2.6 \pm 1.4 \mu \mathrm{m}$.

In order to assess the accuracy of this procedure, $\mathrm{z}$ coordinates were calculated for points within a central circular area with $10 \mathrm{~mm}$ diameter using the two sets of Zernike polynomials derived respectively for the central map alone and for the five maps combined. The average differences between the two sets of $\mathrm{z}$ coordinates remained below $2.4 \mu \mathrm{m}$ in all seven corneas.

\section{Numerical study}

Numerical finite-element simulations were custombuilt for each of the seven eyes included in this study. The simulations included the whole ocular outer tunic (cornea and sclera), and aimed to provide a close representation of in vivo conditions of each eye including the precise adoption of the anterior topography under baseline conditions as well as the value of the normal IOP. However, assumptions had to be made to enable consideration of the non-uniform thicknesses of the cornea and sclera and the regional variation of material properties within the sclera. The corneal and scleral thicknesses were assumed to vary

Table 1 Error of fit with Zernike polynomials with orders between 3 and 8 for central maps and combining central and peripheral maps together

\begin{tabular}{|c|c|c|c|c|}
\hline \multirow[b]{2}{*}{ Zernike order } & \multirow{2}{*}{$\begin{array}{l}\text { Zernike RMS of error }(\mu \mathrm{m}) \\
\text { Whole central map }\end{array}$} & \multicolumn{3}{|c|}{ Map combination RMS of error $(\mu \mathrm{m})$} \\
\hline & & Reduced area of central map ${ }^{a}$ & Whole maps & Reduced area maps* \\
\hline 3 & $9.5 \pm 5.6$ & $4.2 \pm 2.2$ & $14.1 \pm 9.9$ & $9.0 \pm 6.3$ \\
\hline 4 & $2.9 \pm 3.2$ & $0.8 \pm 1.4$ & $11.6 \pm 8.9$ & $7.6 \pm 6.7$ \\
\hline 5 & $2.4 \pm 2.4$ & $0.6 \pm 1.5$ & $11.5 \pm 9.2$ & $7.2 \pm 7.1$ \\
\hline 6 & $1.9 \pm 1.6$ & $0.6 \pm 1.2$ & $11.6 \pm 7.8$ & $6.6 \pm 6.0$ \\
\hline 7 & $1.8 \pm 1.6$ & $0.8 \pm 0.7$ & $10.6 \pm 7.2$ & $5.1 \pm 3.6$ \\
\hline 8 & $1.5 \pm 1.2$ & $0.5 \pm 0.4$ & $10.1 \pm 5.6$ & $4.5 \pm 2.4$ \\
\hline
\end{tabular}

${ }^{a}$ Area of maps excluding data contained with an edge area with $0.8 \mathrm{~mm}$ width 


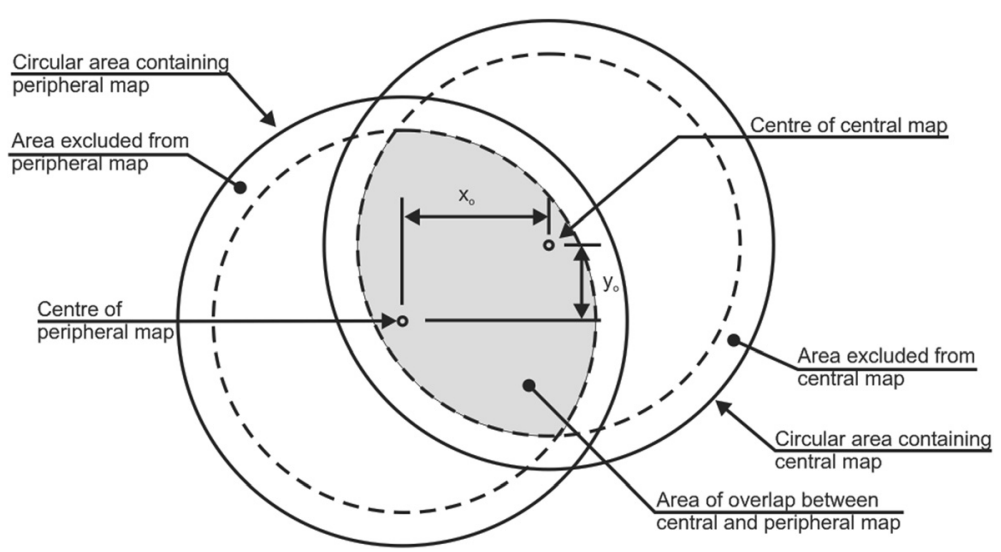

Fig. 1 Combining central and peripheral maps $-x_{0}$ and $y_{0}$ are assumed displacement shifts in $x$ and $y$ directions

linearly from $545 \mu \mathrm{m}$ at the corneal apex to $695 \mu \mathrm{m}$ at the limbus, $590 \mu \mathrm{m}$ at the equator and $960 \mu \mathrm{m}$ at the posterior pole [18-21]. The material properties of the sclera were varied gradually from highest stiffness at the limbus to lowest stiffness at the posterior pole, based on the results of an earlier experimental study and as discussed below [21].

Based on the findings of earlier studies, the simulations used 120,000 six-noded solid elements, arranged in 4 layers and 100 rings, 17 of which were in the cornea, and connected with 75,010 nodes [22], see Fig. 4. While full contact was assumed between the element layers representing the sclera, the weak corneal inter-lamellar adhesion necessitated reducing the adhesion level between the layers of elements representing the cornea to the level observed experimentally in a previous study [23]. The models were restrained against movement in the $\mathrm{Z}$ direction at all equatorial nodes on the external surface and in the $X$ and $\mathrm{Y}$ directions at all nodes along the models' longitudinal axis.

The simulations were designed such that each corneal ring could have different material constants relating to a common constitutive material model, while the sclera was allowed to have only three sets of material constants defining the anterior, equatorial and posterior regions, which extended within rings $18-44,45-72$, and 73-100, respectively; as defined from a previous study [21]. All material models were hyperelastic of the form [24-26]: $\sigma=\mathrm{a}\left(\mathrm{e}^{\mathrm{b} \varepsilon}-1\right)$, where $\sigma$ and $\varepsilon$ were the stress and strain, and $\mathrm{a}$ and $\mathrm{b}$ were constants. Differentiating this equation with respect to strain provides a linear relationship between the tangent modulus, E (a measure of material stiffness) and the stress: $E=d \sigma / d \varepsilon=a b e^{b \varepsilon}=b$ $(\sigma+a)$, which shows that $b$ is the slope of the E- $\sigma$ relationship. Changes in the stiffness between regions could therefore be introduced through proportional changes in the value of $b$ for the different simulations examined.

The material model used in all corneal stromal elements was controlled first according to the relevant subject's age (in years) based on the results of an earlier experimental study [26], which produced values for parameters $\mathrm{a}$ and $\mathrm{b}$ according to the expressions:

$$
\begin{aligned}
& \mathrm{a}=35 \times 10^{-9} \mathrm{age}^{2}+1.4 \times 10^{-6} \text { age }+1.03 \times 10^{-3} \text { and } \\
& \mathrm{b}=0.0013 \text { age }^{2}+0.013 \text { age }+99 .
\end{aligned}
$$

The models for the scleral regions were derived by taking $b_{\text {anterior }}=3 \times b_{\text {central_cornea }}, \quad b_{\text {equator }}=0.88 \times b_{\text {anterior }}$

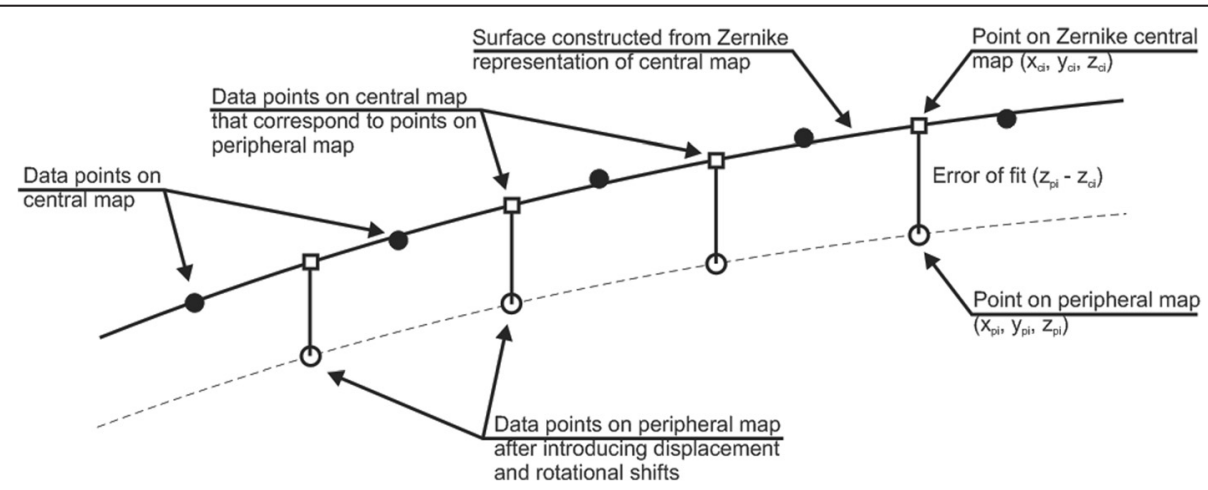

Fig. 2 Fit between a central topography map and a peripheral map in a cross-sectional view 


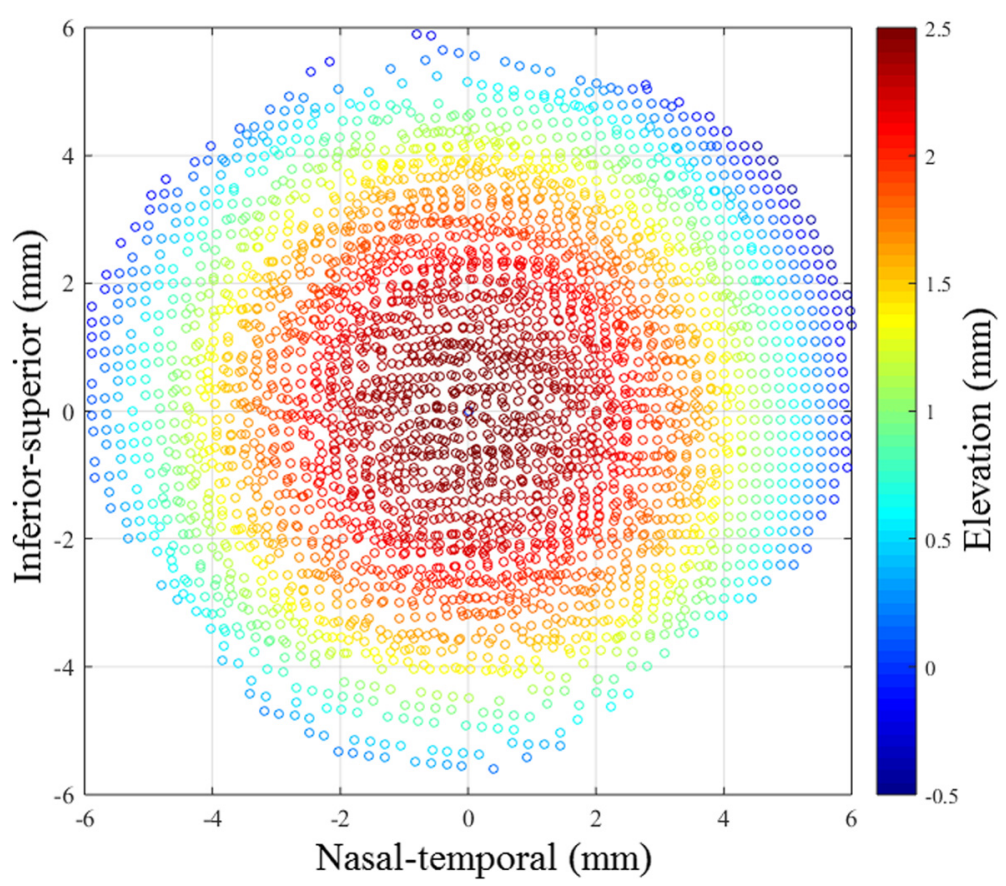

Fig. 3 Example of measured corneal topography in its Cartesian form after the peripheral and central maps has been matched

and $b_{\text {posterior }}=0.85 \times b_{\text {anterion }}$ based on earlier experimental findings $[21,27,28]$. The stress-strain relationships for different parts of the eye model (including individual cornea rings) were created in a Visual Basic tool based on the values of the a and b parameters. While parameter a depended only on the participant's

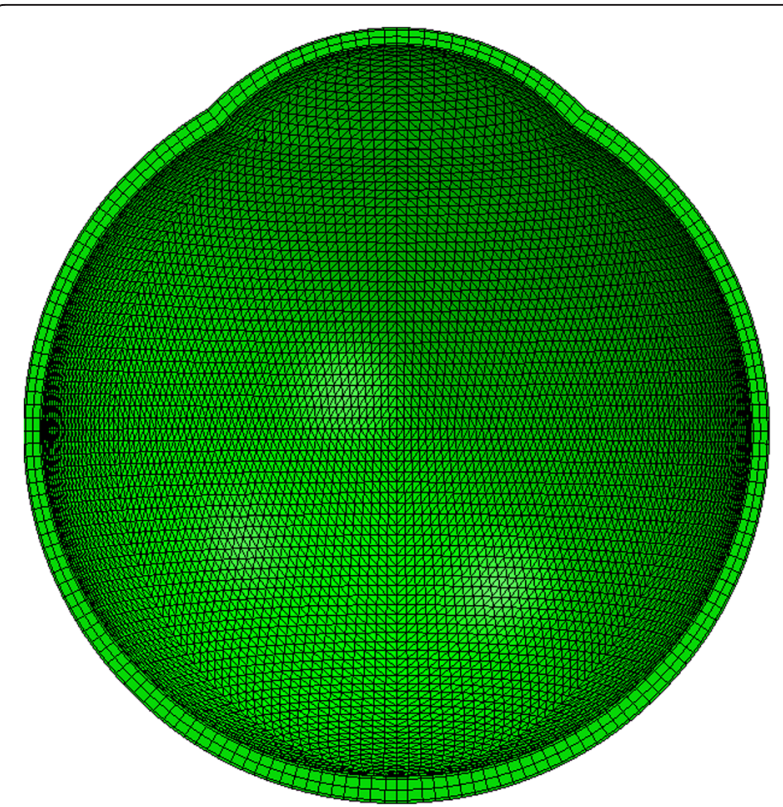

Fig. 4 Cross-section of a numerical model of the eye globe. Model constructed with 100 element rings, 17 of which are in the cornea and 4 layers; providing 1, 2 and 1 layer/s for the epithelium, stroma and endothelium, respectively age and hence remained unchanged, $\mathrm{b}$ was allowed to vary widely and the resulting stress-strain relationships for different parts of the eye were introduced in the analysis files used on the Abaqus software program. The tool was designed to conduct inverse modelling procedures wherein the material properties in different parts of the eye were initially set assuming all cornea element rings had the same stress-strain behavior and that sclera properties followed the trends explained above. The tool used the Particle Swarm Optimization (PSO) method [29] to change the stress-strain relationship of each model segment in the cornea (by changing b parameters) while adopting the objective function: $\sqrt{\frac{1}{n} \sum_{i=1}^{n}\left(z_{\text {numerical }, i}-z_{\text {experimental }, i}\right)^{2}}=\min$, where $n=$ number of anterior nodes on cornea model. The PSO method started with widely-spaced 69 points (particles), each given a "position" or a set of 17 values of b between 0.1 and 10 the initial value of $b_{\text {central cornea }}$ for the 17 cornea element rings. The fitness (value of objective function) of each particle was calculated and used to move the position (or change the $b$ values) to a new position that was expected to have better fitness using the following equation: $\mathrm{B}(\mathrm{t}+1)=\mathrm{B}(\mathrm{t})+\mathrm{v}(\mathrm{t}+1)$, where $\mathrm{B}(\mathrm{t})$ and $\mathrm{B}(\mathrm{t}+1)$ are the $\mathrm{b}$ values of the particles at the current and new iteration, and $v(t+1)$ is a velocity term derived as:

$$
\begin{aligned}
\mathrm{v}(\mathrm{t}+1)= & (\mathrm{w} \times \mathrm{v}(\mathrm{t}))+\left(\mathrm{c}_{1} \times \mathrm{r}_{1} \times(\mathrm{P}(\mathrm{t})-\mathrm{B}(\mathrm{t}))\right) \\
& +\left(\mathrm{c}_{2} \times \mathrm{r}_{2} \times(\mathrm{G}(\mathrm{t})-\mathrm{B}(\mathrm{t}))\right) .
\end{aligned}
$$


In this equation, $\mathrm{P}(\mathrm{t})$ vector represents the particle's best position (with best fitness) found so far, $G(t)$ vector is the best known position found by any particle in the analysis so far, and $\mathrm{w}, \mathrm{c}_{1}, \mathrm{c}_{2}, \mathrm{r}_{1}, \mathrm{r}_{2}$ are constants taken as $0.7,1.4,1.4,0.5,0.6$, based on Microsoft's MDSN guidance. The analysis was repeated for up to 10,000 iterations while monitoring the fitness of the 69 particles considered, and this was sufficient for the analysis to converge on a best solution (min fitness error) in all cases.

\section{Results}

The mean age for the 7 subjects (4 males) was $39.4 \pm$ 17.2 years (range 17-68 years), Table 2 . The normality of this sample is indicated by means, standard deviations and ranges for the central curvature, astigmatism and differences between inferior and superior curvature, which were $42.94 \pm 0.61 \mathrm{D}(42.29-43.90 \mathrm{D}), 0.77 \pm 0.44$ $\mathrm{D}(0.60-1.82 \mathrm{D})$ and $0.14 \pm 0.54 \mathrm{D}(-0.50$ to $0.79 \mathrm{D})$, respectively. The average central corneal radius of curvature and the shape factor (measurement of deviation from a sphere where a shape factor of 1 equates to a perfect sphere) were $7.957 \pm 0.156 \mathrm{~mm}$ and $0.665 \pm$ $0.037 \mathrm{~mm}$ before IOP elevation, and $7.948 \pm 0.149 \mathrm{~mm}$ and $0.695 \pm 0.034 \mathrm{~mm}$ after IOP elevation. The standardized ODM force induced a $98.7 \%$ mean elevation of IOP (Table 2), which is similar to the $99.4 \%$ finding obtained in another study of normal subjects [13], which used the same ODM compressive force setting.

The simulation study started with all corneal elements given the same material model. The resulting distributions of corneal deformation under the increase in IOP were compared to the corresponding experimental data and found to follow a considerably different trend. Figure 5 shows the distribution of corneal deformation for all 7 participants as obtained experimentally and predicted numerically, while assuming uniform corneal

Table 2 Individual increases in IOP for the 7 Subjects

\begin{tabular}{lllccr}
\hline Subject & Gender & $\begin{array}{l}\text { Age } \\
\text { (years) }\end{array}$ & $\begin{array}{l}\text { Baseline IOP } \\
(\mathrm{mmHg})\end{array}$ & $\begin{array}{l}\text { Post ODM IOP } \\
(\mathrm{mmHg})\end{array}$ & \multicolumn{1}{l}{$\begin{array}{l}\text { \% } \\
\text { Increase }\end{array}$} \\
\hline 1 & $\mathrm{~F}$ & 21 & 12.2 & 27.4 & 124.6 \\
2 & $\mathrm{M}$ & 17 & 13.1 & 22.3 & 70.5 \\
3 & $\mathrm{M}$ & 47 & 14.7 & 31.2 & 112.2 \\
4 & $\mathrm{M}$ & 68 & 24.4 & 42.6 & 74.6 \\
5 & $\mathrm{M}$ & 43 & 17.1 & 32.7 & 91.2 \\
6 & $\mathrm{~F}$ & 50 & 13.3 & 29.5 & 121.8 \\
7 & $\mathrm{~F}$ & 30 & 20.7 & 40.5 & 95.7 \\
Average & 39.4 & 16.5 & 32.3 & 98.7 \\
SD & 17.9 & 4.5 & 7.1 & 21.7 \\
\hline
\end{tabular}

$I O P=$ Intraocular pressure, $O D M=$ ophthalmodynamometer stiffness. In all cases, the experimental data showed a clear concentration of deformation in the $2.5 \mathrm{~mm}$ wide corneal circumferential annulus next to the limbus, compared with more uniform distribution in the numerical results, as can be seen in Fig. 5c. The average differences in corneal elevations under IOP increase are also given for individual eyes in Table 3 and shown to be large; up to $11 \mu \mathrm{m}$ or $13 \%$ of the maximum corneal elevation.

Based on these results, the numerical simulations were modified such that individual corneal rings were assigned different material models until the numerical deformation distributions closely matched the experimental data. The least squares method was used to assess the quality of the match while reducing the sum of the squared errors of fit, $\Sigma\left(Z_{\text {experimental }}-Z_{\text {numerical }}\right)^{2}$, to a minimum. The close match with the experimental data is demonstrated in Fig. $5 \mathrm{~d}$ and Table 3 where the average differences in corneal elevation caused by IOP increase are shown to be up to $3.4 \mu \mathrm{m}$ or $3.6 \%$ of maximum corneal elevation, which is considerably lower than for the analyses with uniform stiffness distribution. An example of the close match obtained with non-uniform stiffness distribution for subject 1 is shown in Fig. 6.

The material stiffness distributions that had been required to achieve close match in all 7 eyes examined are depicted in Fig. 7, and show a consistent trend in which the stiffness in the $2.5 \mathrm{~mm}$ wide circumferential zone bounded by the limbus has a considerably lower value compared with the apex. The average behavior presented in Fig. $7 \mathrm{~b}$ shows a stiffness reduction in this zone of $47.3 \%$ compared with the apical stiffness, with a standard deviation (SD) of $10.8 \%(P=0.001)$. There is also a small increase in stiffness of about $3.3 \pm 6.7 \%$ in the paracentral zone formed by an annulus lying between rings with radii of between 2.0 and $3.5 \mathrm{~mm}(P=0.016)$.

\section{Discussion}

Corneal biomechanical properties are heterogeneous, highly anisotropic, non-linear and viscoelastic [30]. Accordingly, the tangent modulus of the cornea varies directionally and regionally, such that a high modulus is exhibited meridionally in the central and paracentral areas, and circumferentially at the limbus, due to the specific arrangement of collagen fibrils [31]. The change of fibril orientation from meridional to circumferential, which takes place within an annulus approximately defined by ring diameters 8.0 and $11.5 \mathrm{~mm}$, suggests a possible material stiffness reduction in this transition zone. This reduction was thought to be partially compensated by a peripheral thickness that is greater than central thickness [32], which may be due to the stromal lamellae interweaving, braiding and branching to form new lamellae on different layers in the peripheral cornea 

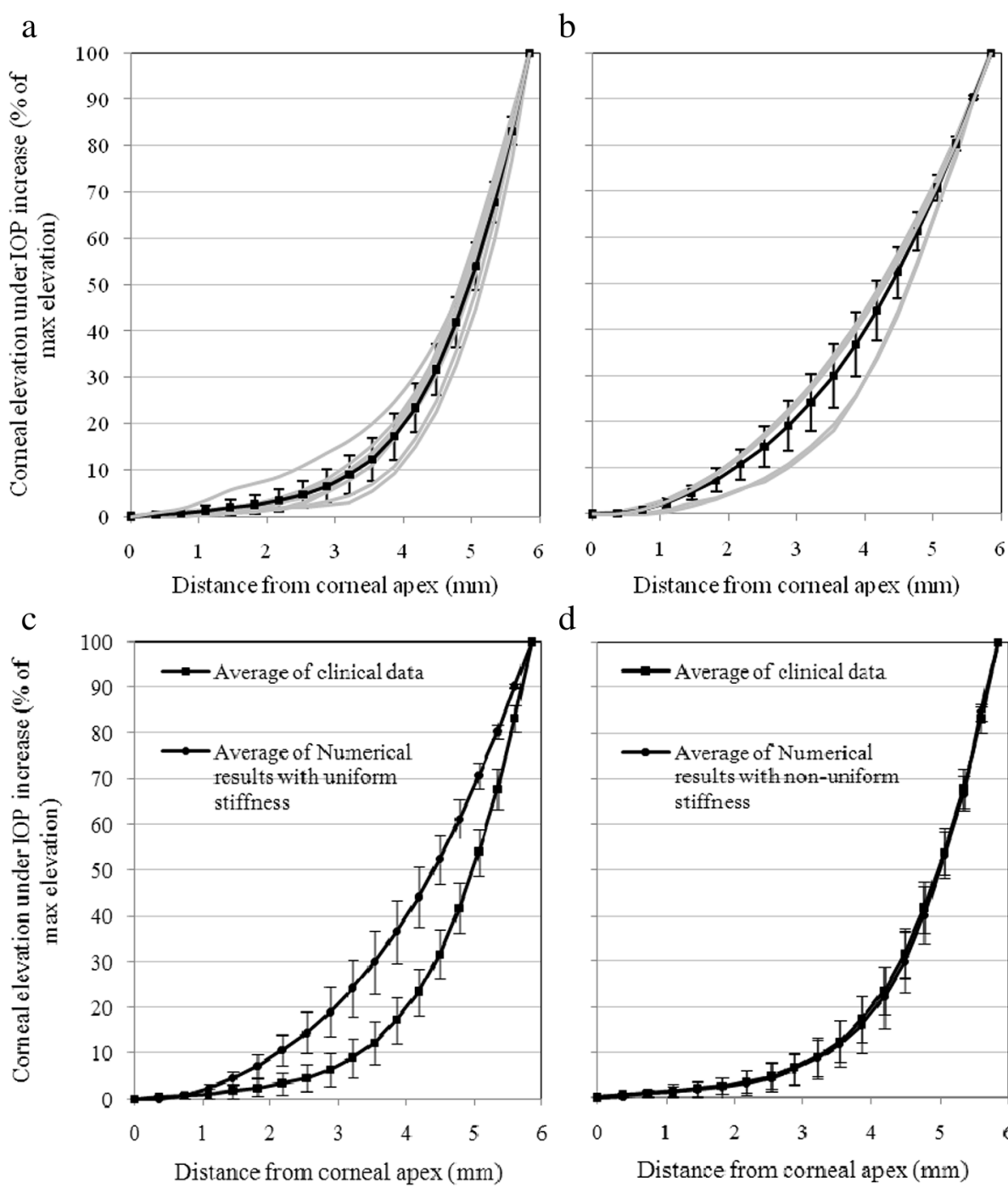

d

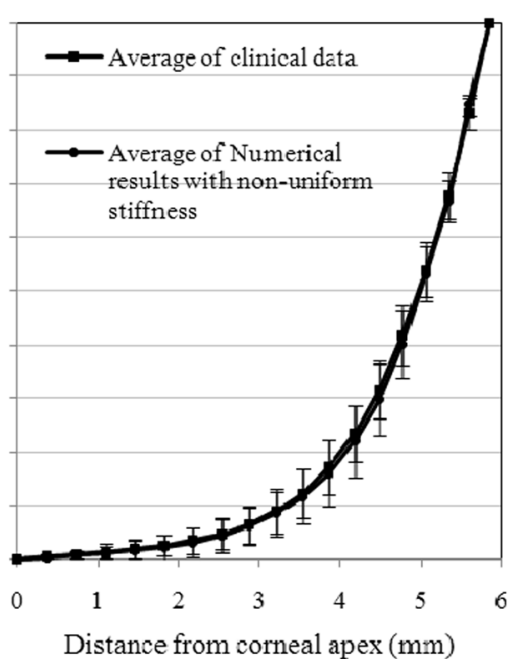

Fig. 5 Elevation data presented as percentage values of maximum elevation. a Experimental data for all seven corneas. b Numerical data assuming uniform corneal stiffness for all seven corneas. c Comparison between average experimental and uniform-stiffness numerical data. d Comparison between average experimental and non-uniform stiffness numerical data with error bars depicting standard deviation values - light lines show individual results while heavy lines depict average distributions

Table 3 Differences in corneal elevation between the experimental and numerical data as obtained from uniform-stiffness and non-uniform-stiffness simulations

\begin{tabular}{lll}
\hline Participant & $\begin{array}{l}\text { Simulations based on uniform stiffness distribution } \\
(\mu \mathrm{m})\end{array}$ & $\begin{array}{l}\text { Simulations based on non-uniform stiffness distribution } \\
(\mu \mathrm{m})\end{array}$ \\
\hline 1 & $11.1 \pm 7.4(0.1-20.9,13.0 \%)$ & $0.5 \pm 0.4(0.0-1.4,0.5 \%)$ \\
2 & $10.2 \pm 7.0(0.2-20.7,11.0 \%)$ & $3.4 \pm 3.3(0.1-8.7,3.6 \%)$ \\
3 & $6.3 \pm 4.7(0.5-12.7,8.1 \%)$ & $1.4 \pm 1.0(0.2-2.8,1.8 \%)$ \\
4 & $2.4 \pm 2.2(0.1-6.3,4.2 \%)$ & $0.8 \pm 0.5(0.0-1.4,1.4 \%)$ \\
5 & $9.8 \pm 6.4(0.2-17.6,12.2 \%)$ & $1.5 \pm 1.5(0.1-4.6,1.8 \%)$ \\
6 & $6.0 \pm 4.6(0.1-12.4,9.0 \%)$ & $0.3 \pm 0.4(0.0-1.5,0.5 \%)$ \\
7 & $6.9 \pm 4.5(0.1-12.3,13.6 \%)$ & $0.8 \pm 0.7(0.1-2.3,1.6 \%)$ \\
\hline
\end{tabular}

Results include the average, standard deviation and range in microns, and the average as a percentage of the maximum experimental corneal elevation for each eye 
a

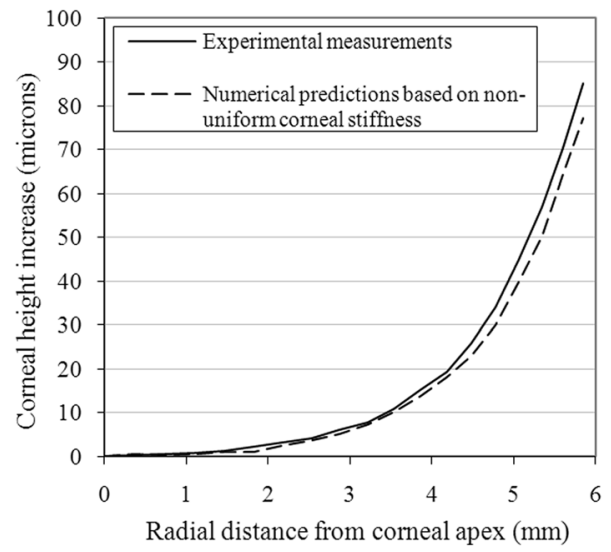

$\mathrm{b}$

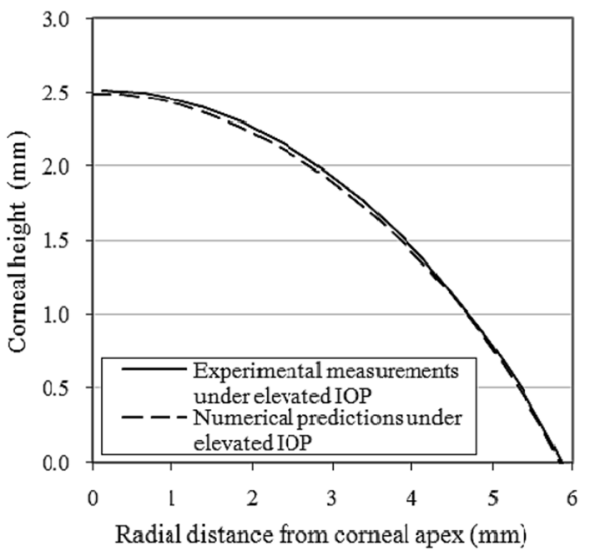

Fig. 6 Example of a match between the experimental elevation data (following IOP increase). The numerical predictions are presented after adjustment of stiffness distributions for Participant 1. a Comparisons of corneal deformation. $\mathbf{b}$ Comparisons of corneal topography along the temporal-nasal center-line

$[3,33]$. However, interweaving and braiding could affect the tissue's tensile stiffness, which is more relevant to the biomechanical action of the cornea under the effect of IOP. In engineering applications, braiding has been found to reduce the tensile stiffness of composite materials by more than $30 \%$ [34]. Similarly, surgically created braiding of connective tissue led to reductions in tangent modulus (a measure of stiffness) of tendons used in the treatment of cruciate ligament injury [35]. Although the effect of braiding has not been studied in corneal tissue, it is possible that it leads to similar reductions in stiffness in the corneal periphery. The expected lower tissue stiffness and the resulting concentration of IOP-induced deformation at the transition zone are compatible with the observation of little noticeable change in refractive power with changes in IOP such as found previously [12]. This type of response appears to be a natural method to ensure stable refractive power is maintained in normal eyes despite significant changes in IOP, which may occur over limited time periods [36].

The current study attempted to quantify the reduction in material stiffness of the corneal periphery that might be caused by both the reduced content of meridional fibrils arrangement of stromal lamellae. The study used topography data obtained in vivo for the left eyes of 7 participants subjected to a temporary IOP elevation. Topography maps, covering the entire cornea and limbus, were obtained before and after

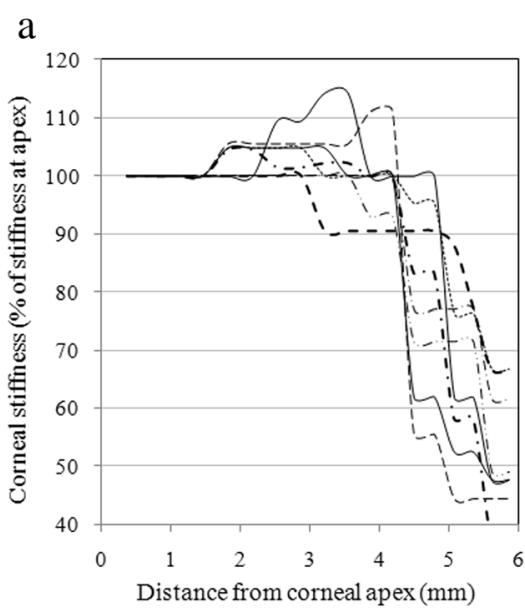

b

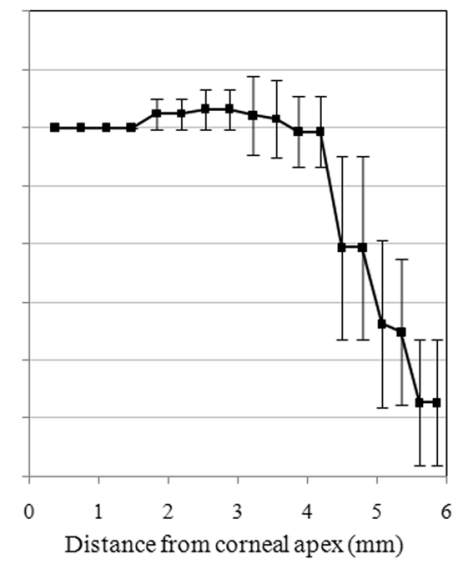

Fig. 7 Corneal stiffness distributions as obtained numerically for all 7 participants. a individual participants. b average distribution for all participants with error bars representing the values of standard deviations 
the increase in IOP and analyzed to determine the profile of resulting corneal deformation. Nonlinear finite-element simulations of the seven eyes were constructed and used to estimate the stiffness distribution across the corneal surface that would be required to lead to deformation profiles similar to those obtained experimentally. Although the study involved a small number of participants, the findings were quite similar across the sample and indicated a significant reduction in material stiffness in a circumferential zone close to the limbus with a width of approximately $2.5 \mathrm{~mm}$. The stiffness reduction in this region was consistent; down by an average of $47.3 \pm 10.8 \%$ ( $P=$ 0.001). These results are comparable with the findings of an earlier study on excised human corneas placed under posterior distending pressure and found to have reduced meridional stiffness in the $1 \mathrm{~mm}$ wide ring of tissue close to the limbus [37]. Compatible results were also obtained in in vitro studies on human and bovine corneas, which concluded that the tissue's tangent modulus was higher at the central and paracentral regions and lower at the periphery $[11,38]$.

The evident correlation between the stiffness distribution across corneal surface and the corresponding stromal microstructure points at the need to consider either the stiffness variation as found in this study or the collagen fibril density and orientation in the finite-element simulations of corneal behavior. Assumptions of corneal homogeneity may lead to unacceptable approximations in behavior prediction.

The methodology used in the study has some potential limitations. The experimental procedure used may have resulted in some deformation of eye shape but uniformity of responses throughout the $360^{\circ}$ of the corneal periphery suggests that this effect was not significantly apparent in the cornea and may have only been restricted to the applanated area of the sclera. The assumed corneal thickness may have an effect on the outcome. However, any error in the assumed central corneal thickness is likely to be reduced when the relative central corneal thickness and peripheral corneal thickness are considered. As it is the relative stiffness that was considered, this assumption is not considered to have a significant effect on the conclusions of the study. Maintaining sclera properties with three discrete regions could affect the results of the study. These effects are limited due to the relatively high stiffness with respect to the cornea.

\section{Conclusion}

The study is an example of how in vivo measurements could yield useful information on corneal biomechanical behavior and provide an alternative to ex vivo tests, which while being increasingly reliable still have the disadvantage of unquantified differences in behavior between ex vivo and in vivo tissue.

The topography changes associated with short-term intraocular pressure elevation in human eyes were used in finite-element numerical simulations and showed that corneal periphery had lower stiffness than the central region.

\section{Competing interests}

The authors declare that they have no competing interests.

\section{Authors' contributions}

AE conducted the numerical analyses and prepared the manuscript, CWM set up the clinical part of the study and took part in the manuscript preparation; CW assisted with the analysis of the numerical results and GCB collected the clinical data. All authors read and approved the final manuscript.

\section{Acknowledgements}

The authors thank Associate Professor David Pye, School of Optometry and Vision Science, University of New South Wales for the loan of the ophthalmodynamometer used for this study. The research was partially supported by the National Institute for Health Research (NIHR) Biomedical Research Centre based at Moorfields Eye Hospital NHS Foundation Trust and UCL Institute of Ophthalmology (AE). The views expressed are those of the author(s) and not necessarily those of the NHS, the NIHR or the Department of Health of the United Kingdom.

\section{Author details}

${ }^{1}$ School of Engineering, University of Liverpool, Brownlow Hill, Liverpool L69 3GH, UK. ${ }^{2}$ National Institute for Health Research (NIHR) Biomedical Research Centre, Moorfields Eye Hospital NHS Foundation Trust and UCL Institute of Ophthalmology, London, UK. ${ }^{3}$ School of Optometry and Vision Science, University of New South Wales, Sydney, Australia.

Received: 30 September 2014 Accepted: 20 November 2015 Published online: 10 December 2015

\section{References}

1. Borcherding MS, Blacik LJ, Sittig RA, Bizzell JW, Breen M, Weinstein HG. Proteoglycans and collagen fibre organization in human corneoscleral tissue. Exp Eye Res. 1975;21:59-70.

2. Komai $Y$, Ushiki T. The three-dimensional organization of collagen fibrils in the human cornea and sclera. Invest Ophthalmol Vis Sci. 1991;32:2244-58.

3. Meek KM, Boote C. The organization of collagen in the corneal stroma. Exp Eye Res. 2004;78:503-12.

4. Kokott W. Über mechanisch-funktionelle Strukturen des Auges. Albrecht v Grafes Arch Ophthalmol. 1938;118:424-85.

5. Meek KM, Boote $C$. The use of $X$-ray scattering techniques to quantify the orientation and distribution of collagen in the corneal stroma. Prog Retin Eye Res. 2009;28:369-92.

6. Newton RH, Meek KM. The integration of the corneal and limbal fibrils in the human eye. Biophys J. 1998;75:2508-12.

7. Newton RH, Meek KM. Circumcorneal annulus of collagen fibrils in the human limbus. Invest Ophthalmol Vis Sci. 1998:39:1125-34.

8. Boote C, Dennis S, Huang Y, Quantock AJ, Meek KM. Lamellar orientation in human cornea in relation to mechanical properties. J Struct Biol. 2005;149:1-6.

9. Meek KM. The cornea and sclera. In: Fratzl P, editor. Collagen, structure and biomechanics. New York: Springer Science; 2008. p. 360-96.

10. Sjontoft $E$, Edmund $C$. In vivo determination of Young's modulus for the human cornea. Bull Math Biol. 1987;49:217-32.

11. Boyce BL, Grazier JM, Jones RE, Nguyen TD. Full-field deformation of bovine cornea under constrained inflation conditions. Biomaterials. 2008;29:3896-904.

12. McMonnies CW, Boneham GC. Corneal curvature stability with increased intraocular pressure. Eye Contact Lens. 2007;33:130-7.

13. McMonnies CW, Boneham GC. Corneal responses to intraocular pressure elevations in keratoconus. Cornea. 2010;29:764-70. 
14. Cho P, Lam AK, Mountford J, Ng L. The performance of four different corneal topographers on normal human corneas and its impact on orthokeratology lens fitting. Optom Vis Sci. 2002;79:175-83.

15. Gloster J. The displacement of intra-ocular fluid during tonometry. Internat Ophthalmol Clin. 1965;5:952-7.

16. Belin MW, Ratliff CD. Evaluating data acquisition and smoothing functions of currently available videokeratoscopes. J Cataract Refract Surg. 1996;22:421-6.

17. Hilmantel G, Blunt RJ, Garrett BP, Howland HC, Applegate RA. Accuracy of the tomey topographic modeling system in measuring surface elevations of asymmetric objects. Optom Vis Sci. 1999;76:108-4.

18. Coster D. Cornea. London: BMJ Publishing Group; 2001

19. Avetisov ES, Savitskaya NF, Vinetskaya MI, Iomdina EN. A study of biochemical and biomechanical qualities of normal and myopic eye sclera in humans of different age groups. Metab Pediatr Syst Ophthalmol. 1983;7:183-8.

20. Olsen TW, Aaberg SY, Geroski DH, Edelhauser HF. Human sclera: thickness and surface area. Am J Ophthalmol. 1998;125:237-41.

21. Elsheikh A, Geraghty B, Alhasso D, Knappett J, Campanelli M, Rama P. Regional variation in the biomechanical properties of the human sclera. Exp Eye Res. 2010;90:624-33.

22. Elsheikh A. Finite element modelling of corneal biomechanical behaviour. J Refract Surg. 2010;26:289-300.

23. Elsheikh A, Ross $S$, Alhasso D, Rama P. Numerical study of the effect of corneal layered structure on ocular biomechanics. Curr Eye Res. 2009;34: 26-35.

24. Greene PR. Stress-strain behavior for curved exponential strips. Bull Math Biol. 1985:47:757-64.

25. Bryant MR, McDonnell PJ. Constitutive laws for biomechanical modeling of refractive surgery. J Biomech Eng. 1996;118:473-81.

26. Elsheikh A, Wang D, Brown M, Rama P, Campanelli M, Pye D. Assessment of corneal biomechanical properties and their variation with age. Curr Eye Res. 2007:32:11-9.

27. Woo SL, Kobayashi AS, Schlegel WA, Lawrence C. Nonlinear material properties of intact cornea and sclera. Exp Eye Res. 1972;14:29-39.

28. Geraghty B, Jones SW, Rama P, Akhtar R, Elsheikh A. Age-related variations in the biomechanical properties of human sclera. J Mech Behav Biomed Mater. 2012;16:181-91.

29. Shi Y, Eberhart RC. Empirical study of particle swarm optimization, Proceedings of the 1999 Congress on Evolutionary Computation. Washington, DC: IEEE; 1999. p. 1945-50.

30. Ethier CR, Johnson M, Ruberti J. Ocular biomechanics and biotransport. Annu Rev Biomed Eng. 2004;6:249-73.

31. Hjortdal JO. On the biomechanical properties of the cornea with particular reference to refractive surgery. Acta Ophthalmol Scand Suppl. 1998;225:1-23.

32. Bron AJ, Tripathi RC, Tripathi BJ. Wolff's Anatomy of the eye and orbit. London: Chapman \& Hall Medical; 1997. p. 1-25.

33. Radner W, Zehetmayer M, Aufreiter R, Mallinger R. Interlacing and crossangle distribution of collagen lamellae in the human cornea. Cornea. 1998; 17:537-43.

34. Ko FK. Tensile strength and modulus of a three-dimensional braid composite. In: Whitney JM, editor. Composite materials: testing and design (seventh conference). Philadelphia: ASTM STP 893; 1986. p. 392-421.

35. Kim DH, Wilson DR, Hecker AT, Jung TM, Brown Jr CH. Twisting and braiding reduces the tensile strength and stiffness of human hamstring tendon grafts used for anterior cruciate ligament reconstruction. Am J Sports Med. 2003;31:861-7.

36. McMonnies CW. Intraocular pressure spikes in keratectasia, axial myopia and glaucoma. Optom Vis Sci. 2008;85:1018-26.

37. Shin TJ, Vito RP, Johnson LW, McCarey BE. The distribution of strain in the human cornea. J Biomech. 1997;30:497-503.

38. Hjortdal JO. Regional elastic performance of the human cornea. J Biomech. 1996:29:931-42

\section{Submit your next manuscript to BioMed Central and we will help you at every step:}

- We accept pre-submission inquiries

- Our selector tool helps you to find the most relevant journal

- We provide round the clock customer support

- Convenient online submission

- Thorough peer review

- Inclusion in PubMed and all major indexing services

- Maximum visibility for your research

Submit your manuscript at www.biomedcentral.com/submit 